\section{France could face 'scientific recession', warns council}

Paris

A leading scientific advisory body to the French government, the Conseil Supérieur de la Recherche et de la Technologie (CSRT), last week strongly criticized France's research budget for 2000, warning that a failure to increase spending "could lead to a scientific recession in the near future".

The council says that the budget, drawn up by the science minister, Claude Allègre, represents an increase of only one per cent from the past year - less than the expected economic growth - to FF54.6 billion (US $\$ 8.6$ billion). "Public spending on research and development is falling behind other developed nations," the CSRT said in a statement.

The council also takes issue with the increase in the National Science Funds, a FF565 million fund established by Allègre last year for large projects or strategies delegated by the ministry. The council has demanded an evaluation of "this interventionist policy, for its impact on research and innovation as well as on the functioning of the research structures".

The CSRT emphasizes the need for these credits to be allocated in an open fashion. But it agrees with the ministry's plans to direct them towards laboratories and projects designed to stimulate technology and innovation.

Recruitment is another part of the budget over which the council expressed concern. France has an ageing scientific workforce, and it is estimated that 50 per cent of its current researchers will reach retirement age in the next ten years.

"The quality of French research in the future depends upon maintaining the quality of recruits in all of its corps," says the council. "The budget does not permit the anticipation of recruitment imposed by the wave of departures to retirement at the end of the next decade."

Further evidence of the tension between Allègre and his advisers comes from the resignation of Giorgio Parisi, a theoretical physicist and professor at La Sapienza University in Rome, from France's National Science Council, which was set up last year to advise the minister on large projects and research strategy. Parisi joins Nobel-prizewinning physicist Claude Cohen-Tannoudji and mathematician Yves Meyer, who resigned last month citing Allègre's refusal to discuss issues before making decisions. Heather McCabe

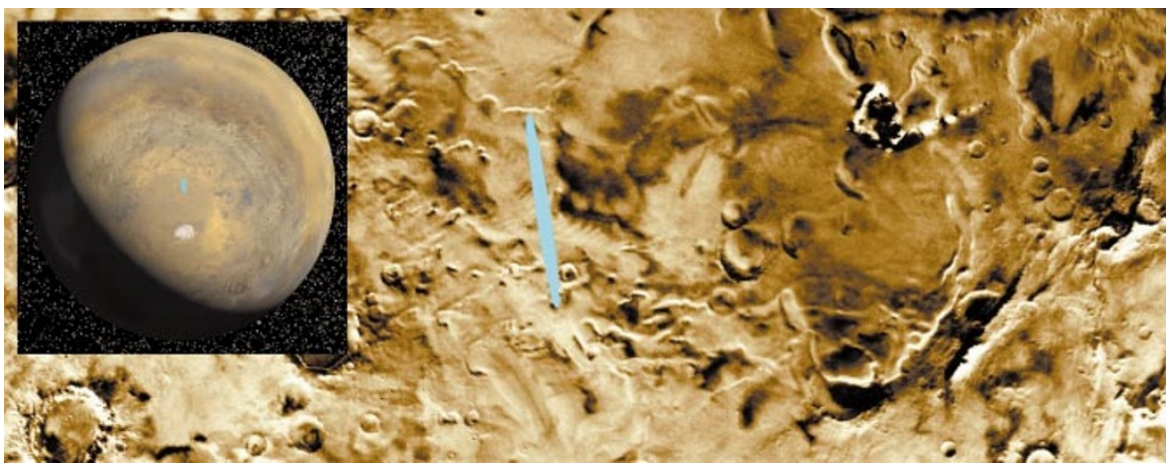

Uncertain terrain: close-up views of planned Mars landing site show it to be rougher than expected.

\title{
Concern over Mars Lander as inquiry reports on Orbiter loss
}

\section{Washington}

The Mars Climate Orbiter was doomed by a combination of understaffing, poor communication, lack of training, and other management problems at the Jet Propulsion Laboratory (JPL) and its prime contractor, Lockheed Martin Astronautics. So concludes a report issued last week by a review board set up to investigate the loss of the \$125 million spacecraft in September.

Managers at the US space agency NASA are scrambling to add oversight staff and to take other corrective actions recommended by the board in preparation for a difficult landing on Mars in just two weeks.

The root cause of the loss of the Orbiter was Lockheed's failure to use metric units as specified by NASA - in software used to calculate the spacecraft's trajectory (see Nature 401, 517; 1999). But the review board found a host of contributing factors. "There were many things in place that should have caught this error," says Arthur Stephenson, director of the agency's Marshall Space Flight Center in Alabama, who chaired the panel.

Spacecraft navigators and operators at JPL had noticed months earlier that their trajectory calculations were slightly off, but failed to appreciate the seriousness of the problem. The board described the navigation team as overworked and isolated from the rest of the JPL project staff.

The team had to handle three Mars missions at once, and were ignorant of key details about the Orbiter, wrongly believing it to have the same characteristics as the Mars Global Surveyor now in orbit around the planet. The navigation team's concerns about discrepancies in the trajectory data were not formally brought to the attention of senior managers.

The board also found that a last-minute trajectory correction manoeuvre that might have saved the spacecraft would not have been possible, because procedures to use it in an emergency were never put in place (see
Nature 401, 415; 1999). NASA plans to develop those procedures for next month's arrival of the Mars Polar Lander.

Lack of communication and unclear lines of authority plagued the project, and still do, according to the report. "A recurring theme in the board's deliberations was 'who's in charge?."

Defensiveness over the loss of the Climate Orbiter is further hindering cooperation between different elements of the project, wrote the panel. JPL director Edward Stone said last week that the lab will add about 30 senior engineers to the project, and has created an advisory group of six senior spacecraft navigators in an all-out effort to ensure that no problems are being overlooked for the 3 December Mars landing.

While the board's inquiry focused on JPL, a separate review of the lab's relations with its contractors, released by the NASA Inspector General in September, highlights problems at Denver-based Lockheed Martin, which is building NASA's fleet of Mars spacecraft.

In the era of 'better, faster, cheaper' projects, the agency is relying more than ever on quality control at companies such as Lockheed. But JPL "does not have adequate policy for monitoring subcontractor performance", according to the Inspector General's report.

Lockheed understaffed the Mars project in its design phase, which may have increased the likelihood of problems being introduced early. The contractor then had people working 70-hour weeks at the end of the project to meet the spacecraft delivery date. "This could have an adverse effect on employee morale and increases the potential for human errors," said the Inspector General.

Stone and NASA science chief Edward Weiler staunchly defended the agency's 'better, faster, cheaper' philosophy last week. Theyblamed the loss of Mars Climate Orbiter on a failure to follow rules and procedures already in place.

Louis Friedman, executive director of the 
Planetary Society and a veteran observer of JPL, also rejects the idea that NASA's Mars programme is underfunded, or that more money will necessarily fix the problem. "You can do things wrong at any price," he says.

But the programme is clearly showing signs of strain. Weiler's office quietly announced its decision last week to postpone indefinitely a planned Mars airplane demonstration flight in 2003, even though industry teams were invited to bid for the project a few weeks ago.

The next landing will be more difficult than the 1997 Pathfinder landing, yet is being done at lower cost. The Mars Polar Lander will use legs rather than airbags to touch down on the planet's surface, and a large boulder in the wrong place could spell disaster.

Recent high-resolution photos of the targeted landing area show that a small fraction of the site appears rougher than expected. Science planners were not worried enough to switch to a back-up site last month but, as with any planetary landing, they will be crossing their fingers at the critical moment.

The Polar Lander will also use a new kind of descent engine with pulsed rocket jets, which raised concern among the members of the accident review board. "This type of powered descent maneuver has always been considered to be very difficult and stressing for a planetary exploration soft landing," they wrote.

But planetary scientist David Paige of the University of California, Los Angeles, a principal investigator for the Lander mission, says he is confident that the JPL team has looked carefully at potential problems. Tony Reichhardt

\section{Professors use web to catch students who plagiarize ...}

\section{Berkeley}

A computer-based service to detect student plagiarism is being used by a growing number of university teachers across the United States, and may soon be tested in Britain. The service was developed by a doctoral candidate at the University of California, Berkeley.

Called Plagiarism.org, the service was launched last spring. It allows academics, journal editors - and even students - to rapidly compare articles against thousands of papers available through the Internet. The Internet has itself made plagiarism far easier through simple cuts and pastes.

One German researcher says he has already found the programme so effective that he plans to scrutinize all manuscripts submitted to his recently launched publication, the Journal of Medical Internet Research (see below).

Plagiarism.org was set up by neurophysiology doctoral student John Barrie. According to Doug Zuidema, head of the Office of Student Conduct at the University of California at Berkeley, the university is negotiating a contract with the company.

"We hope to negotiate an agreement for all faculty and students on the campus to have access to the service," says Zuidema. Plagiarism.org is already negotiating for a pilot study to be carried out at selected British universities through the UK Higher

\section{... and author gets similar paper retracted}

\section{San Diego}

Gunther Eysenbach of the department of clinical social medicine at the University of Heidelberg, and editor of the Journal of Medical Internet Research, plans to publish a report on the uncovering of apparent plagiarism by three physicians from the Royal Infirmary in Edinburgh, Scotland.

After their article, entitled 'The quality of surgical information on the Internet', was published in the August issue of the Journal of the Royal College of Surgeons of Edinburgh, the authors sent out email alerts to those interested in online medicine.

Eysenbach saw the alert, read the paper and recognized phrases in it as appearing to come from an article that he had written for the British Medical Journal in October 1998. "I am not a native English speaker, so it takes hard work to write good English sentences," says Eysenbach. "I recognized the anguish of my work."

Eysenbach also discovered that other material from his journal's website had been used without attribution in the article. Aware of Plagiarism.org (see above), he registered with the US service's website and submitted the article by the Edinburgh physicians, without disclosing what he already knew.

According to Eysenbach, the analysis detected the apparent plagiarism, as well as the improper use of other published material. "About 50 per cent of the article is affected," he claims, adding that the senior author Christopher Oliver, a trauma surgeon at the Royal Infirmary in Edinburgh - initially offered several explanations, from denial to forgetting references.

Ultimately, he says, Oliver agreed to retract the article and apologize. Oliver says that "it was an accident; there was no intent to plagiarize". He added: "I have better things to do than plagiarize his work. It was an omission on my part not to give references."

Although he acknowledges his retraction and apology, Oliver says that "If you ran [this system] on every article [in the medical literature] that comes out, you would find this happening all over the place."

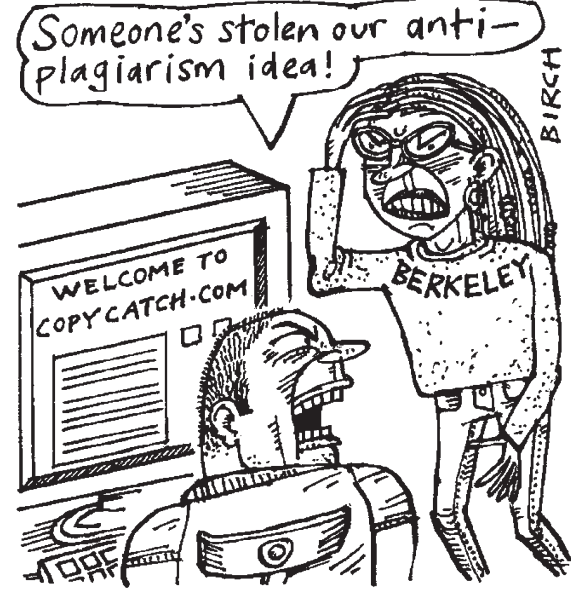

Education Funding Council.

The program originated from Barrie's experience in grading neurobiology papers, when he became suspicious that students were plagiarizing material. In some cases they were taking material from online companies that sell articles over the Internet via websites such as Schoolsucks.com and Cheater.com.

After working as a teaching assistant with psychopharmacologist David Presti, Barrie created the service and enlisted the help of several Berkeley graduates as partners. Last spring, he used the system to check the papers of about 320 juniors and seniors in Presti's upper-division neurobiology class.

When a paper or article is run through the Plagiarism.org vetting system, a printout is generated on which apparently plagiarized material is highlighted. This is done by linking apparently cribbed sections to their sources, typically published articles.

At the beginning of the semester, Presti had told the students that their papers would be checked for plagiarism. Afterwards, Barrie examined the papers and found that 15 per cent of the students had plagiarized material.

One student author from Presti's class, for instance, appeared to have based virtually his whole article on sections of published work lifted from six web addresses.

"Clearly this is a serious problem; we have to do more analysis of it," says Paul Licht, dean of Berkeley's College of Biological Sciences. "I'm not sure whether I'm more discouraged that they committed plagiarism, or that they continued to do so after they were warned."

Presti and Berkeley officials are reviewing possible action against the students. They could be given a failing grade for either the paper or the class, or, more seriously, be charged with violating the code of student conduct.

Rex Dalton 